\title{
Are we expecting too much from the private sector in flood adaptation? Scenario-based field experiments with small- and medium-sized firms in Ho Chi Minh City, Vietnam
}

\author{
Roxana Leitold ${ }^{1}$ (D) - Javier Revilla Diez ${ }^{1}$ (D) $\operatorname{Van}^{\operatorname{Tran}^{2,3}}{ }^{\text {(D) }}$
}

Received: 22 June 2020 / Accepted: 5 October 2020 /Published online: 23 October 2020

(C) The Author(s) 2020

\begin{abstract}
Adaptive governance approaches emphasize the crucial role of the private sector in enabling climate change adaptation. Yet, the participation of local firms is still lacking, and little is known about the conditions potentially influencing firms' adaptation decisions and mechanisms that might encourage private sector engagement. We address this gap with an empirical analysis of the willingness of manufacturing small- and mediumsized enterprises (SMEs) to participate financially in collective flood adaptation in Ho Chi Minh City (HCMC), a hotspot of future climate change risk. Using scenario-based field experiments, we shed light on internal and external conditions that influence potential investments in collective initiatives and explain what role SMEs can play in flood adaptation. We find that direct impacts of floods, perceived self-responsibility, and strong local ties motivate firms to participate in collective adaptation, whereas government support, sufficient financial resources, and previously implemented flood protection strategies reduce the necessity to act collectively. Here, opportunity costs and the handling of other business risks play a decisive role in investment decisions. This study shows that although private sector engagement appears to be a promising approach, it is not a panacea. Collective initiatives on flood adaptation need formal guidance and should involve local business networks and partnerships to give voice to the needs and capacities of SMEs, but such initiatives should not overstretch firms' responsibilities.
\end{abstract}

Keywords Private sector adaptation $\cdot$ Climate change $\cdot$ Flood response $\cdot$ Small-and medium-sized firms $\cdot$ Field experiments $\cdot$ Vietnam

Electronic supplementary material The online version of this article (https://doi.org/10.1007/s10584-02002888-y) contains supplementary material, which is available to authorized users.

Roxana Leitold

r.leitold@uni-koeln.de

Extended author information available on the last page of the article 


\section{Introduction}

Floods are a growing economic concern, particularly for small- and medium-sized enterprises (SMEs), which are a driving force for economic development, employment, and value creation (Halkos et al. 2018). Although the private sector has always suffered from climate disasters (UNISDR 2013), its responses have often been disregarded in global reports on climate change assessments (e.g., IPCC Assessment Reports before 2014). Just recently, the interplay between climate disasters and economic impacts, such as those caused by flooding, has triggered vigorous debates. Following the Fifth IPCC Assessment Report of Working Group II, the critical role that the private sector can play in risk reduction has gained fresh momentum (Abe et al. 2019). Policy frameworks (e.g., Sendai Framework for Disaster Risk Reduction 20152030) and future-oriented scientific research on climate change adaptation (hereafter 'adaptation') call for more integrated and collaborative adaptive strategies that include the private sector (Challies et al. 2016; OECD 2015; The World Bank 2019). Considering projections that climate change will significantly increase future flood risks and that governmental authorities will likely be overburdened with providing integrated flood protection, these new frameworks emphasize the role of private sector knowledge and financial resources in facilitating adequate adaptation measures, including collective flood protection initiatives.

Although recent literature highlights co-responsibility with the private sector, participation of smaller and locally based firms in collective adaptation is still very limited. Unlike large, often multinational firms, most adaptation initiatives do not involve SMEs in formal agreements or even consider their needs and interests (Pauw and Chan 2018). Moreover, the extent to which SMEs are willing to participate in collective action and contribute their capacities toward adaptation measures both remains unclear. Initial findings on their flood responses show that they often only engage in individual coping measures to the neglect of any integrative measures that involve cooperation with other private actors or local governments (Neise and Revilla Diez 2019).

While the relevance of internal firm characteristics for adaptive behavior has already been a subject of analysis on collective adaptation (Neise et al. 2019), little is known about the influence and attitudes of individual decision-makers, the external firm environment, and local complexities (Verrest et al. 2020). Agrawala et al. (2011), Halkos et al. (2018), and Marks and Thomalla (2017) assume that external conditions, such as local partnerships or institutions, play crucial roles that are in need of more detailed investigation. With respect to this lacuna, adaptation research calls for further analytical work to determine what conditions are required for collaborative approaches to work and how private sector engagement could be encouraged and facilitated, with the aim of developing clear guidance for governments and decisionmakers (Averchenkova et al. 2016; Challies et al. 2016; Chen et al. 2013).

Against this backdrop, we see two major challenges: first, the need to better understand what determines firms' decisions regarding active participation in collective flood adaptation, and second the urgent identification of mechanisms and conditions that can be put in place to enhance the role of the private sector (Averchenkova et al. 2016; Clark-Ginsberg 2020).

This study aims to address these challenges by providing an empirical analysis of the willingness of SMEs to participate financially in collective flood adaptation measures. We focus on internal and external considerations and identify those conditions that either facilitate or hamper firms' potential investment. The findings help to clarify what role SMEs can play in adaptation and what kind of incentives should be developed to increase private sector contributions. 
Methodologically, our approach of scenario-based field experiments contributes experimental, ex ante designs that have hardly been used in epistemological analyses of the private sector (Delmas and Aragon-Correa 2016; Linnenluecke and Griffiths 2013). Evidence is sought from experiments with manufacturing SMEs in Ho Chi Minh City (HCMC), which face high flooding risk but have limited financial reserves to invest in improving performance and competitiveness (Trinh and Thanh 2017). The focus on HCMC as one of the most floodprone urban areas in the future serves as a perfect case from which to obtain insights that will be transferrable to other increasingly flood-prone cities, such as Hanoi, Bangkok, Jakarta, and Manila.

We begin by elaborating the conceptual background, indicating the limits of current research, and by developing four hypotheses concerning SMEs' financial contribution toward collective flood adaptation. We continue by detailing our methodological approach and empirical framework. We then proceed to describe and interpret key results from our analysis, before making a few concluding remarks that also point toward future research.

\section{Conceptual background and research framework}

\subsection{The private sector and its potential role in collective flood adaptation: determinants of SME participation}

Flood risk adaptation was long seen as a task exclusively for state and local authorities. However, particularly in developing countries and transition economies, public authorities are increasingly overburdened with tasks of implementing integrated flood protection and financing large-scale measures (Averchenkova et al. 2016; Bisaro et al. 2020). Developing local adaptation is complex and time consuming, as it involves negotiations between state and non-state actors, including local and regional governments, households, and private sector firms, each of which has their own particular needs and interests (Clark-Ginsberg 2020). In Thailand, for example, a high-tech industrial area was flooded in 2011. As a response, the industrial estate planned to build a dike around the area, which led to protests as the project would alter water flows and affect nearby local villages (Druce et al. 2016). For this reason, recent policy trends, as well as an emerging body of literature on adaptive governance, highlight the importance of shifting away from hierarchical and top-down initiatives and toward collaborative, multi-stakeholder, and participatory flood adaptation efforts in order to address the lack of public resources and capacities (Challies et al. 2016; Chen et al. 2013; Clark-Ginsberg 2020; Djalante et al. 2011).

Despite the public nature of measures for flood adaptation, Tompkins and Eakin (2012: 10) point toward "the potential growing need for private provisioning of a public adaptation good", but emphasize that private adaptation for public benefits requires the development of specific institutional mechanisms and collaborations. Collective action among local stakeholders, such as households, firms, social associations, and NGOs, should lead to more effective initiative and flood risk reduction outcomes, based on the pooling of knowledge, the exchange of information, and the sharing of costs and responsibilities (Pahl-Wostl 2009; Pauw and Chan 2018; Verrest et al. 2020). As the private sector is generally equipped with financial resources, unique technological expertise, and organizational flexibility (Halkos and Skouloudis 2019; Linnenluecke et al. 2013; Lo et al. 2019), the issue of what role private firms could play in the future provisioning of public adaptation goods and collective risk governance is gaining attention. 
To date, SMEs' flood adaptations do not typically pursue long-term, cost-intensive strategies, but rather rely on individual, short-term, reactive coping mechanisms - or even inaction. Instead, firms count on large-scale adaptation measures, like dike or sluice systems initiated by public authorities (Neise and Revilla Diez 2019). To understand their decision for or against collective adaptation and to strengthen the potential role of SMEs in collaborative approaches, we must better understand the factors influencing their adaptation strategies (Linnenluecke and Smith 2018). Initial findings in risk reduction and adaptation literature suggest that firms' adaptive behaviors are determined by a variety of factors (Fig. 1). We consider the scope of different adaptation measures, as well as individual and firm-internal factors, institutional conditions, and the external firm environment. We place particular emphasis on relationships with other stakeholders, such as public authorities, civil society, the business community, and NGOs in shaping the adaptive behaviors of SMEs.

First, we emphasize that the costs and the constellation of the actors involved in an adaptation measure jointly determine firms' commitments. With respect to future sea-level rises in low-lying areas, such as HCMC, Tol et al. (2006) argue that individual in situ responses may be insufficient and too costly in the long run. Linnenluecke et al. (2011) thus suggest that more drastic adaptation measures, such as firm relocations, might constitute better alternatives. By contrast, a survey by Geaves and Penning-Rowsell (2016) shows that largescale protection measures, like dike systems, do not attract long-term participation due to a lack of local bonding. Locally funded small-scale flood adaptation schemes, on the other hand, could raise awareness and often encourage the participation of those who benefit from the provision of relevant local infrastructure.

Second, firm-level characteristics such as firm size, business performance, and financial resources have been proven to be critical factors shaping adaptive action (Agrawala et al. 2011; Halkos et al. 2018; Pulver and Benney 2013). Marks and Thomalla (2017) show, for instance, that the recovery of SMEs following a severe flood in Thailand in 2011 was exacerbated by financial constraints including a lack of flood insurance coverage. Trinh and Thanh (2017)

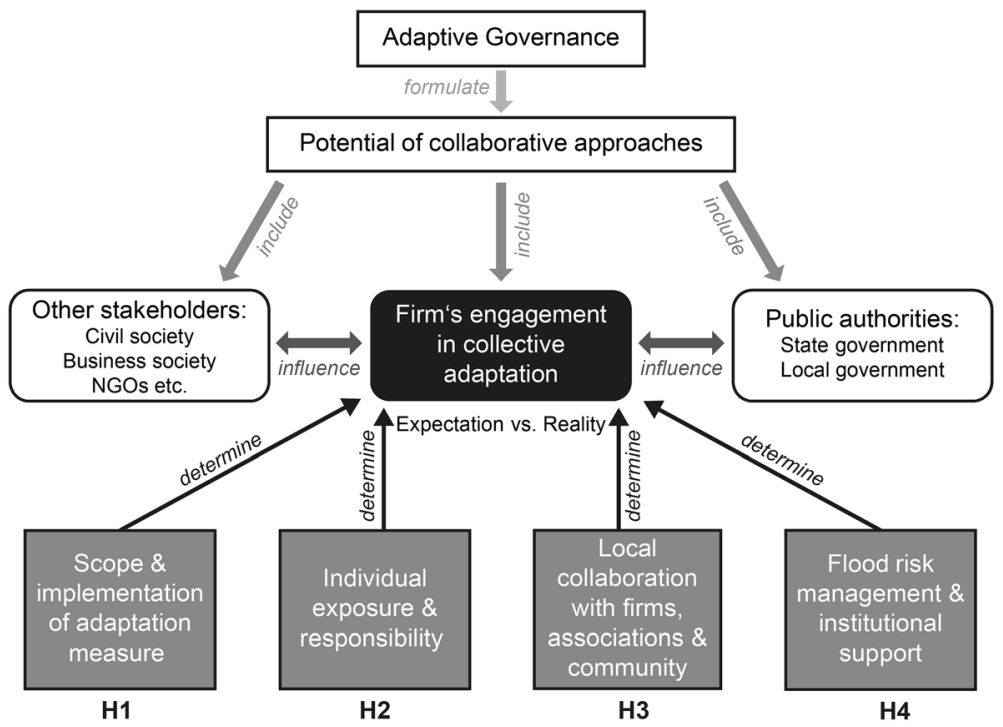

Fig. 1 Research framework and hypotheses (source: authors) 
further argue that SMEs in Vietnam face numerous risks and uncertainties in their daily business life. When assessing flood risks, firms have to weigh these risks against other business risks as well as their limited financial resources. Limited access to such resources, capacity bottlenecks (e.g., in terms of skilled labor), knowledge and technological innovation, as well as increased competition are viewed as primary obstacles to growth and thus as factors shaping vulnerability to crises (Yoshino and Taghizadeh-Hesary 2016).

Even if firms have sufficient internal capacities and resources, they often fail to invest in flood reduction measures (Meinel and Schüle 2018). Hence, the influence of managerial risk perceptions (Linnenluecke et al. 2013) and the division and understanding of responsibilities (Mees 2017) are issues that have come to the fore. Nalau et al. (2015) indicate that an unclear division of adaptation responsibilities could hamper the effective implementation of adaptation measures and management. Along similar lines, Neise et al. (2019) show that the adaptive behavior of manufacturing SMEs in Indonesia is positively related to managers' risk preparedness.

Moreover, empirical studies reveal that prior flood experiences including the degree of impacts are key determinants for whether or not firms will consider flood adaptation in their investment decisions (Agrawala et al. 2011; Kato and Charoenrat 2018; Weinhofer and Busch 2013). In the present context, on the one hand, direct impacts (i.e., the destruction of assets and stocks, suspending production) are based on firms' local exposure through flooded production sites (Pauw 2015). Indirect impacts, on the other hand, are more difficult to capture and refer to supply chain disruptions, logistical problems, and wider effects such as the non-fulfillment of contracts and loss of customer trust (Wedawatta et al. 2014).

Third, the extent of which firms' adaptations are shaped by their local embeddedness, flood risk management, and institutional conditions has been neither extensively explored nor systematized, although these multidimensional factors seem to be strongly interwoven. Lo et al. (2019) emphasize that adaptive action is more likely to be taken when firm owners perceive strong expectations from the community and when social capital is strong. Manufacturing SMEs account for the highest share of locally based businesses, are generally operated by a few individuals, and interact with a wide range of customers, business partners, employees, and local community members (Halkos and Skouloudis 2019; Kato and Charoenrat 2018). Building upon such observations, Pauw and Chan (2018) argue that SMEs could take active responsibilities in localized partnerships that link different actors at the local level and beyond. On this point, state authorities may play significant roles in supporting, guiding, and formulating laws and regulations that could foster collective initiatives and public-private partnerships (Agrawala et al. 2011; Neise et al. 2018). Halkos et al. (2018), for example, found that institutional conditions, support, and guidance all have direct impacts on SMEs' levels of commitment in undertaking measures against extreme weather events. For instance, insufficient promotion activities by the authorities, or insufficient information on the design and implementation of adaptation measures, hinder SMEs' adaptation activities. Moreover, a lack of SME-specific knowledge in external support mechanisms and insufficient guidance by trade associations and business chambers are considered critical obstacles to adaptation.

Institutional frameworks also determine possibilities and costs of participation in investments beyond direct business activities by specifying the approval costs and time frames involved in reconstructing or expanding production facilities to reduce impacts of flooding. In addition, the provision of incentives, such as tax breaks, is considered essential for the development opportunities of SMEs (Wang 2016; Yoshino and Taghizadeh-Hesary 2016). 
In Vietnam, for example, private firms often develop in the shadow of state-owned enterprises and are underserved with respect to institutional support and distributions of resources (Nguyen et al. 2013; Revilla Diez 2016). Thus, it is not only a general question of how the state could support the private sector in flood adaptation, but above all a question of accessibility. In this regard, Marks and Thomalla (2017) and Pathak and Ahmad (2018) analyze the role of the Thai government in supporting SMEs during past flood events, focusing in particular on efforts made by the government to reduce flood risks. They show that the government made little effort to reduce risks at the local level, leaving the primary vulnerabilities of SMEs unaddressed.

\subsection{Hypothesized relationships}

Building on existing empirical evidence, our research framework assumes that the willingness of manufacturing SMEs to participate in collective flood adaptation is determined at different levels (Fig. 1). In order to test the validity of the framework, we hypothesize four positively impacting relationships in which SMEs are more likely to contribute to collective flood adaptation:

Hypothesis 1 (H1): SMEs are more likely to contribute to no- and low-regret measures, rather than to hard, capital-intensive measures.

Hypothesis 2 (H2): SMEs that are directly impacted by floods and consider themselves responsible for reducing flood risks are more likely to contribute.

Hypothesis 3 (H3): SMEs are more likely to contribute when local ties with firms in the neighborhood, business networks, or the community are stronger.

Hypothesis 4 (H4): SMEs are more likely to contribute when they are formally integrated in flood-risk management and receive institutional support.

Explanations for the use of specific variables and parameters to test the hypotheses presented are provided in Section 3.2.

\section{Methods and research design}

Our approach is based on the methodology known as scenario-based field experiments (Neise et al. 2019). This approach combines (1) public-good games in a field-experiment environment by using (2) vignette studies.

First, we chose a public-good game design to test the willingness of SMEs to financially participate in flood adaptation measures under different stakeholder constellations based on the hypothesized relationships (Section 2.2). Public-good games are usually applied in behavioral economics and aim to decipher why collective actions variously succeed or fail. They explore the participant's individual contribution to a public good and examine whether the participant is willing to contribute to the public good or prefers to free-ride on the others' contributions (Ones and Putterman 2007). The rationale behind such contributions is called the voluntary contribution mechanism. In our case, flood adaptation is defined as a so-called discrete public good, whose provision is only guaranteed if several actors cooperate and individually provide certain financial contributions (i.e., threshold value). Hence, the public-good game implies that if the provision point of the adaptation measure is not reached, then a money-back guarantee is 
applied. In this case, the individual contribution of each actor in the experiment is refunded (Groothuis and Whitehead 2009).

In scenario-based field experiments, the public-good game is conducted in a real-world environment. The advantage of this approach is that field experiments can make causal inferences by testing options and strategies in real situations (Delmas and Aragon-Correa 2016). For our study, field experiments with firm owners allow for a better understanding of the factors influencing decisions concerning (non-)engagement in collective adaptation than would be the case with laboratory experiments.

Second, we applied vignette designs in order to examine how different adaptation schemes are assessed. Vignette studies are commonly used in social and political sciences and contain two major components: a vignette experiment as a core element and a small follow-up survey (Atzmüller and Steiner 2010; Rooks et al. 2000). The vignette experiment presents a set of carefully constructed and realistic, but still hypothetical, descriptions of a situation or scenario, which is shown to participants so that they can make their own judgments. The follow-up survey allows researchers to collect additional, respondent-specific characteristics and to control for independent variables in the analysis (Aguinis and Bradley 2014; Atzmüller and Steiner 2010; Oll et al. 2018; Rooks et al. 2000). Vignette scenarios are well-suited to capturing the complex interplay between internal and external factors and for studying the underlying rationales behind (anticipated) decision-making (Oll et al. 2018).

\subsection{Data collection: design and implementation of scenario-based field experiments}

To test the preference for adaptation measures regarding scope (H1), we contextualized four realistic adaptation schemes and developed respective vignettes in an extensive preparatory phase. We also took into account findings from semi-structured interviews with 30 flood-prone manufacturing firms and 9 discussions with local authorities, as well as stakeholder groups, such as NGOs, consulting agencies, research institutions, and business associations, all of which occurred between October 2018 and April 2019. For each of the adaptation schemes, we used the same locational setting, representative of typical flood-prone neighborhoods in HCMC, which were identified during several prior visits of industrial sites in HCMC (for example, see Fig. 2; for the overall experiment setting, see Online Resource 1).

The following adaptation schemes have been jointly developed with our local project partners:

(1) Firm relocation entails large investments and long-term planning. The aim of this collective, proactive strategy is to avoid flood exposure by jointly relocating neighboring firms into small industrial areas within a protected environment. Firms with laborintensive production in HCMC are already relocating due to the government's relocation policies in urban areas (Katzschner et al. 2016).

(2) The construction of a dike system is a hard adaptation measure, ${ }^{1}$ requiring specific technologies and actions, and generally aims at a gradual but long-term protection of riparian zones. This adaptation scheme is based on current flood-control strategies, such as the 'Flood Prevention Planning 1547' that aims to build tidal sluice gates and a dike system east of the Saigon River.

\footnotetext{
${ }^{1}$ See OECD (2015) for a definition and conceptual overview of the different types of adaptation measures ranging from soft to hard.
} 


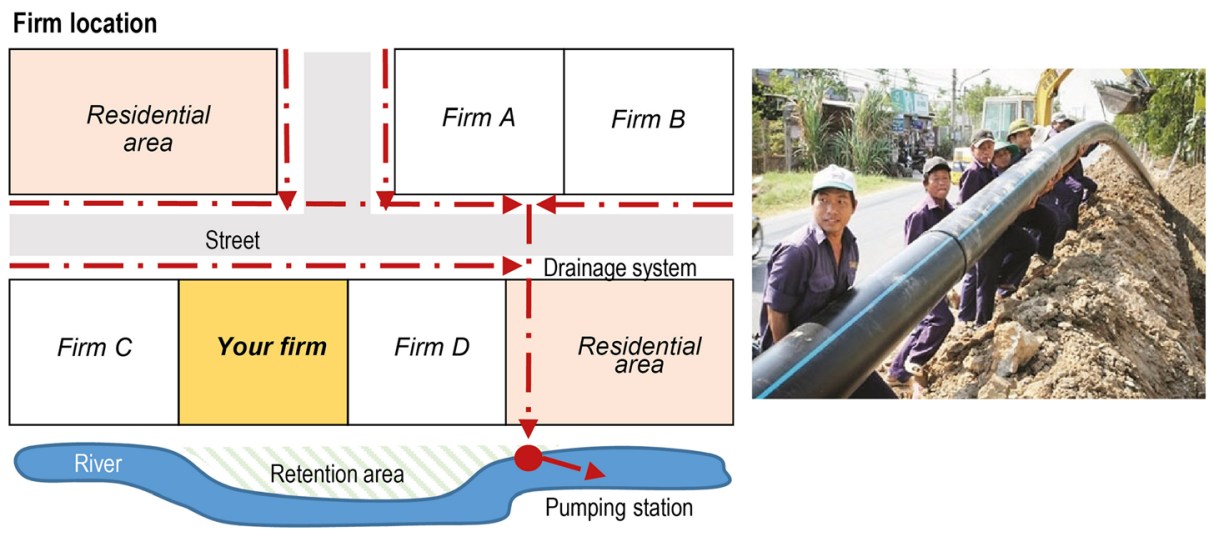

Business losses \& investment options

\begin{tabular}{|l|cc|}
\hline & $\begin{array}{c}\text { without } \\
\text { measure }^{*}\end{array}$ & $\begin{array}{c}\text { with } \\
\text { measure }\end{array}$ \\
\hline Annual loss of revenue & $20 \%$ & $15 \%$ \\
\hline $\begin{array}{l}\text { Total costs } \\
\text { (for neighborhood) }\end{array}$ & 0 & $20 \mathrm{Bn}$ VND \\
\hline Your (fixed) budget & 0 & $0-6,5 \mathrm{Bn}$ VND \\
\hline $\begin{array}{l}\text { The part of your budget that you do not invest is } \\
\text { automatically saved for other investments. }\end{array}$ \\
\hline
\end{tabular}

\author{
* Adaptation measure: \\ Clean and upgrade drainage system within the community \\ Strategy: \\ - Increase drainage capacity \\ - Reduce inundation level
}

Fig. 2 Vignette example: cleaning and upgrading the drainage system (inspired by Neise et al. 2019; photo credit: Vietnamnet Bridge 2016)

(3) Cleaning and upgrading local drainage systems represents a medium-term, but no-regret measure aimed at increasing drainage capacity in industrial neighborhoods. The interviewed firms cited cleaning and upgrading drainage systems as the most urgently needed improvements, as the systems are often clogged. Upgrading and regular maintenance combines a hard measure (upgrading drainage canals) with soft elements (cleaning canals and accesses) and brings benefits even in the absence of climate change.

(4) Implementing and funding a joint awareness program for the local community are an example of a soft, no-regret approach that is already enforced by climate-adaptation strategies for HCMC. In the short term, such programs aim to strengthen local flood-risk management capacity and sensitize community members, for example, by explaining the consequences of discharging waste into river and drainage systems.

To complete the adaptation scenarios, we used five different constellations of actors to finance the adaptation measures (see Table 1).

To test the impact of a joint contribution of the participant with local firms or the local community (H3) on the participant's willingness to participate financially in collective adaptation, we develop two scenarios in which either the residents or other firms in the neighborhood make sufficient contributions to support the adaptation measure. To test the impact of how political guidance influences the participant's willingness to participate financially in collective adaptation (H4), we further test a joint contribution of the participant with local authorities versus a demanded contribution that is punished with a fine for non-compliance. 
Table 1 Overview of scenarios

\begin{tabular}{|c|c|c|c|c|}
\hline & $\begin{array}{l}\text { Firm } \\
\text { relocation }\end{array}$ & $\begin{array}{l}\text { Dike } \\
\text { system }\end{array}$ & $\begin{array}{l}\text { Drainage } \\
\text { system }\end{array}$ & $\begin{array}{l}\text { Awareness } \\
\text { program }\end{array}$ \\
\hline Community contribution (residents make a contribution) & A1 & $\mathrm{B} 1$ & $\mathrm{C} 1$ & D1 \\
\hline $\begin{array}{l}\text { Balanced contribution by firms (other firms contribute the same } \\
\text { amount) }\end{array}$ & $\mathrm{A} 2$ & B2 & $\mathrm{C} 2$ & D2 \\
\hline $\begin{array}{l}\text { Unbalanced contribution by firms (other firms contribute less } \\
\text { than the necessary amount) }\end{array}$ & A3 & B3 & $\mathrm{C} 3$ & D3 \\
\hline Political support (local authorities provide financial incentives) & A4 & B4 & $\mathrm{C} 4$ & D4 \\
\hline $\begin{array}{l}\text { Political pressure (local authorities demand implementation or } \\
\text { impose fines for non-compliance) }\end{array}$ & A5 & B5 & $\mathrm{C} 5$ & D5 \\
\hline
\end{tabular}

The contents of the adaptation schemes and proposed actor constellations were discussed and reviewed by local experts on flood adaptation in HCMC before the survey period. Overall, we conducted scenario-based experiments (20 scenarios per firm) with 63 manufacturing firm owners located in different flood-prone areas in HCMC (e.g., garment and textile manufacturing, metal, iron, and steel production) in the period from September 2019 to March 2020. All firms had fewer than 250 employees. The participants were firm leaders responsible for strategic decisions in manufacturing SMEs. The sample was stratified by firm size, but SMEs were randomly selected within its stratification. For each experiment, we organized appointments in advance by telephone, e-mail, or letter. Since some firm leaders were quite reluctant to participate in the experiments due to confidential concerns and lack of time of availability, local district officers and the Vietnam Chamber of Commerce and Industry (VCCI) supported us with additional firm lists and contact details. Five Vietnamese co-researchers were trained in two extensive work sessions. The standardized scenarios were tested in a week-long trial run that was conducted jointly by Vietnamese and German researchers.

The experiment was divided into two parts. First, we played the 20 scenarios with each participant (one-shot, public-good game) to determine the general preference for adaptation measures and to identify the scenario conditions under which firms are willing to invest part of their budget in collective adaptation. Illustrations of the scenario scheme (scenario cards, see Online Resource 1) were shown to participants to ensure that they fully understood the scenario situation. Second, we conducted a follow-up survey with each participant to collect additional independent variables on firm characteristics related to out hypotheses, including individual flood exposure and perceived responsibility $(\mathrm{H} 2)$, neighborhood relations $(\mathrm{H} 3)$, and the institutional environment (H4).

\subsection{Data analysis: multilevel regression analysis}

The scenario-based field experiments generated 1020 observations. Missing values reduced the number of experiments to 51, which is slightly lower compared with other field experiments with SMEs or farmers (e.g., Alpizar et al. 2011; Neise et al. 2019; Saenger et al. 2013). However, the total number of observations is comparable due to a higher number of scenario options, and thus provides a valid basis for obtaining meaningful results at each level of analysis (i.e., scenario characteristics, firm characteristics, commune characteristics). Only the cross-causality relationship of factors between different levels influencing participants' decision-making was not statistically reliable due to the limited number of experiments and would lead to weak interpretations. 
As each participant answered 20 scenarios, the scenario data are nested within the firm and commune characteristics. Thus, we worked with hierarchically structured data, applying a logit-multilevel regression analysis. Running a standard ordinary least squares regression would lead to spatial autocorrelation and violation of the assumption of independence for scenario observations that are clustered in the same higher levels (Hox et al. 2017; Sohns and Revilla Diez 2018). Applying a multilevel analysis allowed us to consider the interdependencies and differences between the scenario characteristics, the firms, and the level of the commune where the firms are located (Neise et al. 2019; Park et al. 2012).

For the analysis, "willingness to participate in collective flood adaptation" was used as a dichotomous-dependent variable, where 1 indicates that the threshold of the required contribution for each scenario had been reached and 0 means that firms were unwilling to contribute sufficiently (for details of the variables, see Online Resource 2).

In order to gain an impression of the preference for adaptation schemes (H1), we designed two variables, "relocation option" and "soft measure". The latter includes the option of developing a joint awareness program in the firm's neighborhood.

To test H2, first the dummy variable "high flood exposure" was used to indicate that the firm had been impacted by flooding at least once a year in the previous 5 years. Second, we generated the dummy variable "firm responsibility", which serves as an indicator of the firm's high perceived responsibility to undertake flood protection and risk reduction measures. We controlled for revenue development ("expected growth"), "firm size" by number of employees, and "good financial resources" for individual measures to combat flooding, as Marfai et al. (2015) found the type of adaptation measures implemented to be strongly determined by economic considerations.

We tested the influence of local ties (H3) using different explanatory variables. Following Neise et al. (2019), we used "balanced contribution by firms", which demonstrates that the private sector contribution needed was distributed fairly among all firms, and "community contribution", indicating whether the residents contributed financially to the adaptation scheme at the scenario level. "Unbalanced contribution" served as a control variable.

At firm level, we used "collaboration with local firms" and "collaboration with business associations" to test whether different business-related collaborations and structures in the neighborhood influenced firms' willingness to contribute. We controlled for "collaboration with district firms" and "collaboration with suppliers". Additionally, the variable "stakeholder collaboration" shows whether firms were already collaborating with local community groups, NGOs, or consultancies in order to enhance their competitiveness, thereby testing the influence of local ties with civil society.

With regard to H4, we designed six variables. First, we tested for "political support" at the scenario level, which means that the government provided financial support for the implementation of flood protection. Second, we used "support during flood events" at the firm level, which indicates whether firms had already received government support due to flooding. "Access to capital" shows whether firms had access to external sources such as loans from banks or microcredit institutions (see Trinh and Thanh 2017). In addition, we used "collaboration with People's Committee" as a proxy for cooperation with the city council. All four variables serve as indicators for flood-risk management and institutional support. Third, based on the assumption that private firms remain underserved compared with both state-owned (SOE) and foreign firms (FDI) with respect to access to institutional support and resources (Nguyen et al. 2013), we used the variables "SOEs" and "FDIs" to test the effect of the existence of state-affiliated and foreign-related firms at the commune level. The general control 
variable "individual flood adaptation" was intended to indicate that firms were unwilling to participate in collective initiatives because they had already invested in individual adaptation measures to reduce flood impacts (Neise et al. 2019). To test for multicollinearity, we calculated the variance inflation factors (VIFs) for the independent variables. Since the test resulted in an average VIF of 2.15 , multicollinearity can be rejected.

\section{Findings and discussion}

\subsection{Firms' contribution and preferences for adaptation scenarios}

The descriptive data analysis shows that in $48.6 \%$ of all scenarios conducted, SMEs were willing to contribute to flood adaptation measures. This first insight coincides with average results obtained in one-shot public-good games, which amounts to $40-60 \%$ of personal endowment (Chaudhuri 2011). However, the results show slight differences between adaptation schemes and substantial differences regarding financial participation by the community, other firms, and the state (see Table 2). The willingness to contribute to joint firm relocation and the dike system was below average, whereas the drainage system and particularly the awareness program were favored. Regarding the actor constellations, the study shows that a balanced contribution of all firms was preferred (A2, B2, C2, D2). By contrast, an unbalanced contribution by the other firms leads to a well below average willingness to contribute (A3, B3, $\mathrm{C} 3, \mathrm{D} 3)$. In the scenarios where either the community (A1, B1, C1, D1) or the government (A4, B4, C4, D4) supports flood protection financially, the contribution share was below the overall average. Scenarios in which firms have to pay an annual fine if they do not invest in adaptation measures led to a below-average contribution (A5, B5, C5, D5).

We substantiate the descriptive impressions with the analytical results of the three-level logistic regression. A closer look at the fixed effects of the scenario level allows us to interpret the direction of the influence of estimated scenario characteristics on investment decisions by calculating the odds ratios (see $\mathrm{m} 3$ in Table 3 ).

Generally, SMEs prefer low-cost, soft measures to cost-intensive and hard measures, which supports H1. They are significantly less likely to participate in the relocation scenario, while they tend to be more willing to invest into scenarios with soft measures. These initial findings align with the analysis conducted by Agrawala et al. (2011), which stresses that soft adaptation

Table 2 Contribution to different adaptation schemes and actor constellations (share as \% per scenario)

\begin{tabular}{lll}
\hline & Contribution & No contribution \\
\hline Adaptation schemes & & \\
Firm relocation & 40.8 & 59.2 \\
Dike system & 48.2 & 51.8 \\
Drainage system & 50.2 & 49.8 \\
Awareness program & 55.3 & 44.7 \\
Actor constellation & & 43.1 \\
Community contribution & 56.9 & 27.9 \\
Balanced contribution by firms & 72.1 & 94.6 \\
Unbalanced contribution by firms & 5.4 & 38.2 \\
Political support & 61.8 & 52.9 \\
Political pressure & 47.1 & \\
\hline
\end{tabular}


Table 3 Multilevel regression results for willingness to participate in collective flood adaptation

\begin{tabular}{|c|c|c|c|c|}
\hline Fixed effects & $\begin{array}{l}\text { Odds ratio } \\
\text { (standard error) } \\
\text { m0 }\end{array}$ & $\begin{array}{l}\text { Odds ratio } \\
\text { (standard error) } \\
\text { m1 }\end{array}$ & $\begin{array}{l}\text { Odds ratio } \\
\text { (standard error) } \\
\text { m2 }\end{array}$ & $\begin{array}{l}\text { Odds ratio } \\
\text { (standard error) } \\
\text { m3 }\end{array}$ \\
\hline \multicolumn{5}{|l|}{ Scenario characteristics } \\
\hline Relocation option & & $0.551 * *(0.139)$ & $0.552 * *(0.139)$ & $0.552 * *(0.139)$ \\
\hline Soft measure & & $1.443 *(0.316)$ & $1.446^{*}(0.317)$ & $1.445 *(0.317)$ \\
\hline Community contribution & & $1.900 * *(0.486)$ & $1.882 * *(0.477)$ & $1.883 * *(0.478)$ \\
\hline $\begin{array}{l}\text { Balanced contribution by } \\
\text { firms }\end{array}$ & & $5.505 * * *(1.511)$ & $5.412 * * *(1.478)$ & $5.401 * * *(1.474)$ \\
\hline $\begin{array}{l}\text { Unbalanced contribution } \\
\text { by firms }\end{array}$ & & $0.011 * * *(0.006)$ & $0.009 * * *(0.005)$ & $0.008 * * *(0.005)$ \\
\hline Political support & & $2.633 * * *(0.682)$ & $2.600 * * *(0.670)$ & $2.600 * * *(0.669)$ \\
\hline \multicolumn{5}{|l|}{ Firm characteristics } \\
\hline Firm size & & & $1.026 * * *(0.006)$ & $1.030 * * *(0.006)$ \\
\hline Expected growth & & & $2.816^{* *}(1.205)$ & $2.327 * *(0.997)$ \\
\hline Good financial resources & & & $0.410 * *(0.175)$ & $0.417 * *(0.176)$ \\
\hline High flood exposure & & & $17.146 * * *(9.600)$ & $16.810 * * *(9.252)$ \\
\hline $\begin{array}{l}\text { Individual flood } \\
\text { adaptation }\end{array}$ & & & $0.034 * * *(0.020)$ & $0.039 * * *(0.019)$ \\
\hline Firm responsibility & & & $2.033(0.928)$ & $2.220 *(1.008)$ \\
\hline $\begin{array}{l}\text { Support during flood } \\
\text { events }\end{array}$ & & & $0.074 * * *(0.045)$ & $0.089 * * *(0.053)$ \\
\hline Access to credits & & & $0.331 * * *(0.136)$ & $0.367 * *(0.153)$ \\
\hline Collaboration local firms & & & $2.117 *(0.926)$ & $2.108 *(0.908)$ \\
\hline $\begin{array}{l}\text { Collaboration district } \\
\text { firms }\end{array}$ & & & $0.797(0.396)$ & $0.728(0.356)$ \\
\hline Collaboration suppliers & & & $0.513(0.302)$ & $0.486(0.280)$ \\
\hline Collaboration BA & & & $4.783 * * *(2.586)$ & $3.997 * *(2.187)$ \\
\hline Collaboration PC & & & $3.562 * *(1.798)$ & $3.232 * *(1.656)$ \\
\hline Stakeholder collaboration & & & $0.956(0.710)$ & $1.145(0.880)$ \\
\hline \multicolumn{5}{|l|}{ Commune characteristics } \\
\hline $\begin{array}{l}\text { Number of state-owned } \\
\text { enterprises }\end{array}$ & & & & $0.890(0.236)$ \\
\hline $\begin{array}{l}\text { Number of foreign firms } \\
\text { (FDIs) }\end{array}$ & & & & $0.963(0.024)$ \\
\hline Constant & $-0.795(0.212)$ & $0.857(0.344)$ & $0.155^{* *}(0.143)$ & $0.311(0.304)$ \\
\hline \multicolumn{5}{|l|}{ Random effects } \\
\hline Commune var.(_cons) & $0.138(0.339)$ & $0.154(0.974)$ & $6.974(2.794)$ & $6.072(2.433)$ \\
\hline $\begin{array}{l}\text { Commune }>\text { firms } \\
\text { var.(_cons) }\end{array}$ & $1.366(0.445)$ & $4.380(1.459)$ & $0.111(0.172)$ & $0.098(0.167)$ \\
\hline \multicolumn{5}{|l|}{ Model fit statistics } \\
\hline Observations & 1020 & 1020 & 1020 & 1020 \\
\hline ICC commune & 0.029 & 0.020 & 0.672 & 0.642 \\
\hline ICC firm & 0.285 & 0.560 & 0.011 & 0.010 \\
\hline Prob $>\mathrm{Chi}^{2}$ & 0.000 & 0.000 & 0.000 & 0.0000 \\
\hline Deviance & 1262.457 & 893.670 & 852.364 & 848.599 \\
\hline
\end{tabular}

$* * *$ Significant at $1 \%$ level $(p<0.01)$; **significant at 5\% level $(p<0.05)$; *significant at $10 \%$ level $(p<0.1)$. Source: Own calculation based on survey conducted and Vietnam Enterprise Survey Data 2017

and low/no regret measures are the most common climate adaptation actions implemented by the private sector. These measures are not exclusive and usually do not require high financial investment. Hard measures, on the other hand, are usually implemented by large corporations that own long-term assets and thus urgently need to consider future climate impacts.

It is unsurprising that, in almost $60 \%$ of the scenarios, the participants are unwilling to participate in a joint relocation and tend to react rather cautiously to flood-induced relocation. 
This can be explained by the costly, long-term orientation of a relocation process, especially as SMEs operate according to short-term financial reward cycles and often cannot afford to relocate (Neise and Revilla Diez 2019). Relocation as an in situ and short-term adaptation measure is not feasible, but is rather a response to a general economic business orientation or is induced by a range of external stressors, incentives, or political conditions (Linnenluecke et al. 2011).

\subsection{Firms' flood exposure and responsibility to take action}

The multilevel analysis shows that the variables "high flood exposure" and "firm responsibility" achieved positive statistical significance (see $\mathrm{m} 3$ in Table 3 ). The participation in collective flood adaptation increases when the firm has already experienced direct flood impacts within the last 5 years. SMEs that consider themselves responsible for flood protection alongside state authorities are also more willing to participate in collective initiatives. These analytical results support H2, as decision-makers in SMEs focus on their individual vulnerability and their past flood experience (Kato and Charoenrat 2018; Pinkse and Gasbarro 2016).

Moreover, as Halkos et al. (2018) stress concerning adaptation at the individual level, managerial perceptions seem to be key parameters for collective engagement. In this study, only $31 \%$ of firms rate themselves as highly responsible for flood adaptation and protection. Even if firms suffer from indirect flood impacts, such as flooded streets and disrupted supply chains, they usually see the authorities or the management of industrial parks as being responsible for infrastructure and flood protection measures outside the company premises. Thus, the active role assigned to the private sector for more collaborative and integrated flood risk reduction management (Averchenkova et al. 2016; McKnight and Linnenluecke 2016; Pauw 2015) crucially depends on strengthened role awareness.

Though not the main focus of our analysis, some of the firm performance characteristics that we controlled for yielded interesting results. As anticipated, expected revenue growth and firm size were found to have a significantly positive effect. This implies that the larger and more competitive a firm is, the more willing it is to participate financially. Interestingly, however, good financial resources for adaptation measures and the implementation of individual adaptation significantly reduce the probability of participating in collective initiatives. Collective adaptation is thus the preferred response when firms are directly impacted by flooding and have insufficient financial resources to invest in individual measures.

\subsection{Firms' embeddedness in local collaborations and structures}

The results of the multilevel analysis show that local ties play an important role for the engagement of SMEs in collective adaptation and support H3. The involvement in local business networks yields positive, strongly significant results, while collaboration with neighboring firms yields positive, but only slightly significant results (see $\mathrm{m} 3$ in Table 3 ). The latter result should therefore be interpreted with caution. In addition, SMEs prefer to participate in scenarios in which all firms in the neighborhood share investment costs fairly.

Neise et al. (2019), however, find that pure business cooperation with other companies does not yield significant results for investment in collective measures in Jakarta, Indonesia. A closer look at the various local relationships in the firm's immediate environment is therefore necessary. Our survey reveals that SMEs have strong links to their neighborhoods. On average, about $65 \%$ of their employees live in close proximity to the firm, and local relations 
often go beyond business contacts. What can be further argued is that floods are generally perceived as a local challenge. With regard to discussing and solving common local challenges (e.g., environmental and infrastructural issues), local business associations are assigned a particularly important role. Above all, they strengthen local knowledge through regular exchanges of information, which leads to growing flood risk awareness. Supporting arguments for this claim are also highlighted by Pahl-Wostl (2009), who suggests that non-state actor groups and informal networks in governance systems support social learning and strengthen information exchange. In a similar vein, Marfai et al. (2015) reveal that the lack of coordination between stakeholders is a key factor that increases flood vulnerability. In this regard, business associations consolidate firms' concerns and act as a mouthpiece when dealing with local authorities.

However, the willingness of SMEs to participate in adaptation is not influenced by collaborations with other non-state stakeholders (e.g., civil society organizations); yet, they significantly prefer scenarios with a joint investment among neighborhood residents. This result can be explained by the fact that efforts made by civil society organizations, environmental consultancies, or NGOs to reduce the risk of flooding focus more on households or urban development challenges than on business concerns. A perspective that considers firms as vulnerable to flooding is still fairly novel (Pinkse and Gasbarro 2016). The descriptive results of our study support these claims, as we find little cooperation between companies and other stakeholders. Only $18 \%$ of the sampled SMEs report that they exchange information, for example, with civil society organizations or NGOs. Manufacturing companies, in particular, have so far been seen as greater sources of environmental and climate risks, rather than potential sources of local risk reduction.

\subsection{The role of risk management systems and institutional support}

We hypothesized that the roles of risk management and institutional support are highly important for fostering local collective action. But with respect to $\mathrm{H} 4$, our analysis reveals differentiated results (see $\mathrm{m} 3$ in Table 3).

First, SMEs significantly prefer scenarios in which local authorities make financial contributions to adaptation measures. In addition, existing collaborations with the city council lead to a higher probability of participation in collective adaptation measures. Due to its political legitimacy (i.e., formulation of rules and laws, consideration of public preferences), the role of the state in supporting adaptation measures still seems decisive. In this vein, Djalante et al. (2011) and Neise et al. (2018) emphasize the ongoing need for strong governmental action and institutional impulses. In the follow-up survey, firms rated local authorities (42\%) and state authorities $(28 \%)$ as the most important actor for flood risk reduction. This supports the findings of Geaves and Penning-Rowsell (2016), who suggest that society still sees flood management as public priority goods to be provided by the state.

Second, this study shows that institutional support in the event of floods and access to external credit significantly reduce the likelihood of firms contributing to collective action. In other words, firms that already receive financial support for flood protection are less willing to participate collectively. This could be explained in two ways. On the one hand, although access to external financial resources for private sector action on climate change is highlighted (Pulver and Benney 2013; Trinh and Thanh 2017), firms use their internal resources for other aspects of business development if they already 
receive support from the local authorities. In our follow-up survey, the risk of natural hazards ranks only fifth behind general economic crisis, competition, lack of skilled workers, and regulatory framework in terms of relevance. In the follow-up survey, the firms also reported on plans to invest in new machinery (67\%), staff training (53\%), technological innovations (47\%), expansion (49\%), and relocation (31\%) of production sites in addition to other measures to combat natural hazards $(55 \%)$.

On the other hand, public authorities do not yet see SMEs as a priority for private sector involvement and do not focus on creating incentives to encourage SME involvement in disaster risk management. Pathak and Ahmad (2018) reach the same conclusion that there was a serious lack of communication between the local government and impacted local SMEs following a flood disaster in Thailand. In the same vein, Christoplos et al. (2017) argue that recent decentralization policy is redefining disaster risk governance in Vietnam. Local authorities have discretionary powers in implementing national policy, leading to the privatization of former government functions and new relationships with the private sector. However, the overall objective of strengthening public-private partnerships is primarily aimed at large flagship manufacturing and insurance companies.

Third, contrary to expectations it can be noted that the number of SOEs and foreign firms in the commune does not yield significant results and therefore appears to be irrelevant for the willingness of SMEs to participate. Possible explanations for this result are, first, that the majority of SOEs and foreign firms are not located in flood exposed areas, but rather in protected industrial parks, and therefore have no direct influence on the adaptation behaviors of local SMEs. Second, the units where the data were collected may have been too small to investigate local or even regional factors influencing firms' collective adaptation decisions. On a larger scale, however, a bias in favor of multinational and state-owned firms can still be observed (Leitold and Revilla Diez 2019; Nguyen et al. 2013; Revilla Diez 2016). SOEs are still seen as lead players in the economy and should therefore also play a lead role in managing and implementing flood adaptation. But it is not possible to conclusively state whether the presence of SOEs or foreign firms create incentives or stakeholder pressure for SMEs to engage in collective action.

\section{Concluding remarks}

This study provides an empirical, scenario-based analysis of the willingness of manufacturing SMEs to invest in collective flood adaptation measures in HCMC. The results show that SMEs generally prefer to invest in low-cost, soft measures. SMEs that are already directly impacted by flooding and perceive themselves responsible for flood adaptation are more willing to participate in collective adaptation. Further, interaction with neighboring firms, local business networks, or the city council is a driving factor for participation. In contrast, existing support mechanisms tend to inhibit collective action. If SMEs have sufficient capital or already receive support from the authorities, they still prefer to act individually. Opportunity costs and the handling of other business risks therefore seem to play a critical role in investment decisions. Our case study shows that SMEs have not yet exhausted their potential for reducing future flood risk. Collective adaptation is largely only a response when firms are directly impacted by regular floods and have insufficient resources to deal with the effects individually. However, due to 
climate change, flood risks are becoming increasingly pressing and SMEs themselves are called upon to take action. We therefore give three policy-related recommendations for the engagement of SMEs in flood adaptation in Ho Chi Minh City and other flood-prone urban areas such as Jakarta, Bangkok or Manila.

First, encouraging SMEs to prioritize flood risk and its management is crucial for collective adaptation. Nevertheless, the responsibilities of SMEs in collective adaptation should not be overstretched, as they must continue to invest in business-related capacities in order to contribute to sustainable regional development through job creation and tax payments. Most SMEs have little financial leeway, and investment in adaptation measures would simultaneously mean less investment in new machinery and technological innovation. The participation of SMEs is therefore no panacea and can only be successful as supplementary to and embedded within public efforts.

Second, SMEs need formal support and effective guidance to improve adaptation, even if public authorities are not directly involved in implementation. Although decentralization tendencies in transition economies such as Vietnam evolve toward greater openness of collaborative risk reduction responsibilities, the state is still seen as a major actor in initiating flood risk reduction. Creating conducive conditions (e.g., political programs, tax incentives, and legislative mandates for public-private partnerships) that facilitate SME participation might not be a new challenge, but it requires genuine action and a clear allocation of responsibilities.

Third, we underline that private sector engagement should not only focus on the cofinancing of large adaptation measures, but on introducing small-scale measures that meet local needs. Here, the creation of strong networks and partnerships between local SMEs, multiplier organizations, and state actors can play a crucial role. For instance, business associations should act as a voice for SMEs, promote their concerns, and trigger the transfer of information and support from higher political levels.

In terms of methodology, our analysis is based on a hypothetical, simplified design of adaptation scenarios, which are strongly adapted to the local context. Thus, we recommend that similar experiments be conducted in different field contexts to improve external validity. As firm characteristics and the impact of the institutional setting are based on the participants' personal assessments, the results should be interpreted accordingly. Unfortunately, we are unable to examine the depth of local cooperation and its influence on collective adaptation, which opens up a relevant avenue for further research.

Acknowledgments We would like to thank our colleagues at the Centre for Economic and Financial Research, University of Economics and Law in Ho Chi Minh City, Vietnam for their valuable support in organizing and conducting interviews and field experiments. We also would like to thank the research participants for sharing their insights and perspectives, and the DECIDER team and Thomas Neise for the general support in the project. Further, we acknowledge the constructive comments of the three anonymous reviewers.

Authors' contributions All authors contributed to the study conception and design. Material preparation, data collection, and analysis were performed by Roxana Leitold (principal author) and Van Tran. The first draft of the manuscript was written by Roxana Leitold, and all authors commented on previous versions of the manuscript. All authors read and approved the final manuscript.

Funding Open Access funding enabled and organized by Projekt DEAL. The contribution to this research by Roxana Leitold and Javier Revilla Diez is based on the project 'DECisions for Adaptive Pathway Design and the Integrative Development, Evaluation and Governance of Flood Risk Reduction Measures in Transforming Urban-Rural-Systems (DECIDER)', funded by the Federal Ministry of Education and Research (BMBF), CLIENT II (01LZ1703D). The contribution to this research by Van Tran was funded by the University of Economics and Law, Vietnam National University Ho Chi Minh City, Vietnam. 
Data availability Due to confidentiality agreements, the survey data are not publicly accessible, but can be requested from the first author.

\section{Compliance with ethical standards}

Conflict of interest The authors declare that they have no conflict of interest.

Code availability We used Stata 15 for the multilevel regression analysis. The application code can be requested from the first author.

Open Access This article is licensed under a Creative Commons Attribution 4.0 International License, which permits use, sharing, adaptation, distribution and reproduction in any medium or format, as long as you give appropriate credit to the original author(s) and the source, provide a link to the Creative Commons licence, and indicate if changes were made. The images or other third party material in this article are included in the article's Creative Commons licence, unless indicated otherwise in a credit line to the material. If material is not included in the article's Creative Commons licence and your intended use is not permitted by statutory regulation or exceeds the permitted use, you will need to obtain permission directly from the copyright holder. To view a copy of this licence, visit http://creativecommons.org/licenses/by/4.0/.

\section{References}

Abe Y, Zodrow I, Johnson DAK, Silerio L (2019) Risk informed and resilient development: engaging the private sector in the era of the Sendai framework. Prog Disast Sci 2:100020. https://doi.org/10.1016/j. pdisas.2019.100020

Agrawala S, Carraro M, Kingsmill N, Lanzi E (2011) Private sector engagement in adaptation to climate change: approaches to managing climate risks. OECD Environ Work Pap. https://doi.org/10.1787/5kg221jkf1g7-en

Aguinis H, Bradley KJ (2014) Best practice recommendations for designing and implementing experimental vignette methodology studies. Organ Res Methods 17:351-371. https://doi.org/10.1177/1094428114547952

Alpizar F, Carlsson F, Naranjo MA (2011) The effect of ambiguous risk, and coordination on farmers' adaptation to climate change-a framed field experiment. Ecol Econ 70:2317-2326

Atzmüller C, Steiner PM (2010) Experimental vignette studies in survey research. Methodology 6:128-138. https://doi.org/10.1027/1614-2241/a000014

Averchenkova A, Crick F, Kocornik-Mina A, Leck H, Surminski S (2016) Multinational and large national corporations and climate adaptation: are we asking the right questions? A review of current knowledge and a new research perspective. Wiley Interdiscip Rev Clim Chang 7:517-536. https://doi.org/10.1002/wcc.402

Bisaro A, de Bel M, Hinkel J, Kok S, Bouwer LM (2020) Leveraging public adaptation finance through urban land reclamation: cases from Germany, the Netherlands and the Maldives. Clim Chang 160:671-689. https://doi.org/10.1007/s10584-019-02507-5

Challies E, Newig J, Thaler T, Kochskämper E, Levin-Keitel M (2016) Participatory and collaborative governance for sustainable flood risk management: an emerging research agenda. Environ Sci Pol 55:275-280. https://doi.org/10.1016/j.envsci.2015.09.012

Chaudhuri A (2011) Sustaining cooperation in laboratory public goods experiments: a selective survey of the literature. Exp Econ 14:47-83. https://doi.org/10.1007/s10683-010-9257-1

Chen J, Chen THY, Vertinsky I, Yumagulova L, Park C (2013) Public-private partnerships for the development of disaster resilient communities. J Conting Crisis Manag 21:130-143. https://doi.org/10.1111/14685973.12021

Christoplos I, Le Ngoan D, Le Sen TH, Huong NTT, Lindegaard LS (2017) The evolving local social contract for managing climate and disaster risk in Vietnam. Disasters 41:448-467. https://doi.org/10.1111/disa.12215

Clark-Ginsberg A (2020) Disaster risk reduction is not 'everyone's business': evidence from three countries. Int J Disast Risk Reduction 43:101375. https://doi.org/10.1016/j.ijdrr.2019.101375

Delmas MA, Aragon-Correa JA (2016) Field experiments in corporate sustainability research. Organ Environ 29: 391-400. https://doi.org/10.1177/1086026616677827

Djalante R, Holley C, Thomalla F (2011) Adaptive governance and managing resilience to natural hazards. Int J Disast Risk Sci 2:1-14. https://doi.org/10.1007/s13753-011-0015-6

Druce L, Moslener U, Gruening C, Pauw WP, Connell R (2016) Demystifying adaptation finance for the private sector. UNEP Finance Initiative, Geneva 
Geaves LH, Penning-Rowsell EC (2016) Flood risk management as a public or a private good, and the implications for stakeholder engagement. Environ Sci Pol 55:281-291. https://doi.org/10.1016/j. envsci.2015.06.004

Groothuis PA, Whitehead JC (2009) The provision point mechanism and scenario rejection in contingent valuation. Agric Resour Econ Rev 38:271-280

Halkos G, Skouloudis A (2019) Investigating resilience barriers of small and medium-sized enterprises to flash floods: a quantile regression of determining factors. Clim Dev 19:1-10. https://doi.org/10.1080 $/ 17565529.2019 .1596782$

Halkos G, Skouloudis A, Malesios C, Evangelinos K (2018) Bouncing back from extreme weather events: some preliminary findings on resilience barriers facing small and medium-sized enterprises. Bus Strateg Environ 27:547-559. https://doi.org/10.1002/bse.2019

Hox JJ, Moerbeek M, van de Schoot R (2017) Multilevel analysis: techniques and applications. Routledge

Kato M, Charoenrat T (2018) Business continuity management of small and medium sized enterprises: evidence from Thailand. Int J Disast Risk Reduction 27:577-587. https://doi.org/10.1016/j.ijdrr.2017.10.002

Katzschner A, Schwartze F, Thanh B, Schmidt M (2016) Introduction to Ho Chi Minh City. In: Katzschner A, Waibel M, Schwede D, Katzschner L, Schmidt M, Storch H (eds) Sustainable Ho Chi Minh City: Climate Policies for Emerging Mega Cities. Springer; Springer International Publishing, Cham, pp 5-17

Leitold R, Revilla Diez J (2019) Exposure of manufacturing firms to future sea level rise in Ho Chi Minh City, Vietnam. J Maps 15:13-20. https://doi.org/10.1080/17445647.2018.1548385

Linnenluecke MK, Griffiths A (2013) Firms and sustainability: mapping the intellectual origins and structure of the corporate sustainability field. Glob Environ Chang 23:382-391. https://doi.org/10.1016/j. gloenvcha.2012.07.007

Linnenluecke M, Smith T (2018) Adaptation of MSMEs to climate change: a review of the existing literature. In: Schaer C, Kuruppu N (eds) Private-sector action in adaptation: Perspectives on the role of micro, small and medium size enterprises, UNEP DTU Partnership, Copenhagen, pp 19-27

Linnenluecke MK, Stathakis A, Griffiths A (2011) Firm relocation as adaptive response to climate change and weather extremes. Glob Environ Chang 21:123-133. https://doi.org/10.1016/j.gloenvcha.2010.09.010

Linnenluecke MK, Griffiths A, Winn MI (2013) Firm and industry adaptation to climate change: a review of climate adaptation studies in the business and management field. WIREs Clim Change 4:397-416. https://doi.org/10.1002/wcc.214

Lo AY, Chow ASY, Liu S, Cheung LTO (2019) Community business resilience: adaptation practice of microand small enterprises around the Pearl River Estuary. Clim Chang 157:565-585. https://doi.org/10.1007 /s10584-019-02562-y

Marfai MA, Sekaranom AB, Ward P (2015) Community responses and adaptation strategies toward flood hazard in Jakarta, Indonesia. Nat Hazards 75:1127-1144. https://doi.org/10.1007/s11069-014-1365-3

Marks D, Thomalla F (2017) Responses to the 2011 floods in Central Thailand: perpetuating the vulnerability of small and medium enterprises? Nat Hazards 87:1147-1165. https://doi.org/10.1007/s11069-017-2813-7

McKnight B, Linnenluecke MK (2016) How firm responses to natural disasters strengthen community resilience. Organ Environ 29:290-307. https://doi.org/10.1177/1086026616629794

Mees H (2017) Local governments in the driving seat?: a comparative analysis of public and private responsibilities for adaptation to climate change in European and North-American cities. J Environ Policy Plan 19: 374-390. https://doi.org/10.1080/1523908X.2016.1223540

Meinel U, Schüle R (2018) The difficulty of climate change adaptation in manufacturing firms: developing an action-theoretical perspective on the causality of adaptive inaction. Sustainability 10:569. https://doi. org/10.3390/su10020569

Nalau J, Preston BL, Maloney MC (2015) Is adaptation a local responsibility? Environ Sci Pol 48:89-98

Neise T, Revilla Diez J (2019) Adapt, move or surrender? Manufacturing firms' routines and dynamic capabilities on flood risk reduction in coastal cities of Indonesia. Int J Disast Risk Reduction 33:332-342. https://doi.org/10.1016/j.ijdrr.2018.10.018

Neise T, Revilla Diez J, Garschagen M (2018) Firms as drivers of integrative adaptive regional development in the context of environmental hazards in developing countries and emerging economies - a conceptual framework. Environ Plann C 36:1522-1541. https://doi.org/10.1177/2399654418771079

Neise T, Sambodo MT, Revilla Diez J (2019) Are micro-, small- and medium-sized enterprises willing to contribute to collective flood risk reduction? Scenario-based field experiments from Jakarta and Semarang, Indonesia. Organ Environ:1-24. https://doi.org/10.1177/1086026619875435

Nguyen TV, Le NTB, Bryant SE (2013) Sub-national institutions, firm strategies, and firm performance: a multilevel study of private manufacturing firms in Vietnam. J World Bus 48:68-76

OECD (2015) Climate change risks and adaptation: linking policy and economics, Paris 
Oll J, Hahn R, Reimsbach D, Kotzian P (2018) Tackling complexity in business and society research: the methodological and thematic potential of factorial surveys. Bus Soc 57:26-59. https://doi.org/10.1177 $/ 0007650316645337$

Ones U, Putterman L (2007) The ecology of collective action: a public goods and sanctions experiment with controlled group formation. J Econ Behav Organ 62:495-521. https://doi.org/10.1016/j.jebo.2005.04.018

Pahl-Wostl C (2009) A conceptual framework for analysing adaptive capacity and multi-level learning processes in resource governance regimes. Glob Environ Chang 19:354-365. https://doi.org/10.1016/j. gloenvcha.2009.06.001

Park SE, Marshall NA, Jakku E, Dowd AM, Howden SM, Mendham E, Fleming A (2012) Informing adaptation responses to climate change through theories of transformation. Glob Environ Chang 22:115-126. https://oi.org/10.1016/j.gloenvcha.2011.10.003

Pathak S, Ahmad MM (2018) Role of government in flood disaster recovery for SMEs in Pathumthani province, Thailand. Nat Hazards 93:957-966. https://doi.org/10.1007/s11069-018-3335-7

Pauw WP (2015) Not a panacea: private-sector engagement in adaptation and adaptation finance in developing countries. Clim Pol 15:583-603. https://doi.org/10.1080/14693062.2014.953906

Pauw P, Chan M (2018) Multistakeholder partnerships for adaptation: the role of micro, small and medium enterprises. In: Schaer C, Kuruppu N (eds) Private-sector action in adaptation: Perspectives on the role of micro, small and medium size enterprises, UNEP DTU Partnership, Copenhagen, pp 99-109

Pinkse J, Gasbarro F (2016) Managing physical impacts of climate change: an attentional perspective on corporate adaptation. Bus Soc 58:333-368. https://doi.org/10.1177/0007650316648688

Pulver S, Benney T (2013) Private-sector responses to climate change in the Global South. WIREs Clim Change 4:479-496. https://doi.org/10.1002/wcc. 240

Revilla Diez J (2016) Vietnam 30 years after Doi Moi: achievements and challenges. Z Wirtsch 60:121-133. https://doi.org/10.1515/zfw-2016-0035

Rooks G, Raub W, Selten R, Tazelaar F (2000) How inter-firm co-operation depends on social embeddedness: a vignette study. Acta Sociol 43:123-137

Saenger C, Qaim M, Torero M, Viceisza A (2013) Contract farming and smallholder incentives to produce high quality: experimental evidence from the Vietnamese dairy sector. Agric Econ 44:297-308. https://oi. org/10.1111/agec.12012

Sohns F, Revilla Diez J (2018) Explaining micro entrepreneurship in rural Vietnam - a multilevel analysis. Small Bus Econ 50:219-237. https://doi.org/10.1007/s11187-017-9886-2

The World Bank (2019) Vietnam: toward a safe, clean, and resilient water system, Washington, DC

Tol RSJ, Bohn M, Downing TE, Guillerminet M-L, Hizsnyik E, Kasperson R, Lonsdale K, Mays C, Nicholls RJ, Olsthoorn AA (2006) Adaptation to five metres of sea level rise. J Risk Res 9:467-482

Tompkins EL, Eakin H (2012) Managing private and public adaptation to climate change. Glob Environ Chang 22:3-11. https://doi.org/10.1016/j.gloenvcha.2011.09.010

Trinh PTT, Thanh ND (2017) Development characteristics of SME sector in Vietnam: evidence from the Vietnam Enterprise Census 2006-2015. VEPR [Viet Nam Institute for Economic and Policy Research, supported by the Friedrich Naumann Foundation for Freedom], Working Paper WP-18, Hanoi

UNISDR (2013) From shared risk to shared value - the business case for disaster risk reduction. Global assessment report on disaster risk reduction, Geneva, Switzerland

Verrest H, Groennebaek L, Ghiselli A, Berganton M (2020) Keeping the business going: SMEs and urban floods in Asian megacities. Int Dev Plan Rev 42:241-261. https://doi.org/10.3828/idpr.2020.3

VIETNAMNET Bridge (2016) Vietnam seeks capital for water supply and drainage systems. https://english. vietnamnet.vn/fms/environment/164115/vietnam-seeks-capital-for-water-supply-and-drainage-systems.html

Wang Y (2016) What are the biggest obstacles to growth of SMEs in developing countries?: - an empirical evidence from an enterprise survey. Borsa Istanbul Rev 16:167-176. https://doi.org/10.1016/j. bir.2016.06.001

Wedawatta G, Ingirige B, Proverbs D (2014) Small businesses and flood impacts: the case of the 2009 flood event in Cockermouth. J Flood Risk Manag 7:42-53. https://doi.org/10.1111/jfr3.12031

Weinhofer G, Busch T (2013) Corporate strategies for managing climate risks. Bus Strateg Environ 22:121-144. https://doi.org/10.1002/bse.1744

Yoshino N, Taghizadeh-Hesary F (2016) Major challenges facing small and medium-sized enterprises in Asia and solutions for mitigating them. ADBI Working Paper 564, Tokyo

Publisher's note Springer Nature remains neutral with regard to jurisdictional claims in published maps and institutional affiliations. 


\section{Affiliations}

Roxana Leitold ${ }^{1} \cdot$ Javier Revilla Diez ${ }^{1} \cdot \operatorname{Van}_{\operatorname{Tran}^{2,3}}$

1 Institute of Geography, University of Cologne, Cologne, Germany

2 University of Economics and Law, Ho Chi Minh City, Vietnam

3 Vietnam National University, Ho Chi Minh City, Vietnam 